\title{
Correction to: Train-the-Trainers in hand hygiene: a standardized approach to guide education in infection prevention and control
}

\author{
Ermira Tartari 1,2,3 ${ }^{12}$ Carolina Fankhauser ${ }^{1}$, Sarah Masson-Roy ${ }^{1,4}$, Hilda Márquez-Villarreal $^{5}$, \\ Inmaculada Fernández Moreno ${ }^{6}$, Ma Luisa Rodriguez Navas ${ }^{7}$, Odet Sarabia ${ }^{8}$, Fernando Bellissimo-Rodrigues ${ }^{9}$, \\ Marcela Hernández-de Mezerville ${ }^{10}$, Yew Fong Lee ${ }^{2,11}$, Mohammad Hassan Aelami ${ }^{12}$, Shaheen Mehtar ${ }^{13}$, \\ Américo Agostinho', Liberato Camilleri ${ }^{14}$, Benedetta Allegranzi ${ }^{15}$, Daniela Pires ${ }^{1,16}$ and Didier Pittet ${ }^{1 *}$
}

\section{Correction to: Antimicrob Resist Infect Control https://doi.org/10.1186/s13756-019-0666-4}

The original article [1] contained a misspelling in author, Fernando Bellissimo-Rodrigues's name which has since been corrected.

\footnotetext{
Author details

'Infection Control Programme and WHO Collaborating Centre on Patient Safety, University of Geneva Hospitals and Faculty of Medicine, 4 Rue Gabrielle-Perret-Gentil, 1211 Geneva, Switzerland. Institute of Global Health, Faculty of Medicine, University of Geneva, Geneva, Switzerland. ${ }^{3}$ Faculty of Health Sciences, University of Malta, Msida, Malta. ${ }^{4}$ Hotel-Dieu de Lévis, Lévis, Canada. ${ }^{5}$ Department of Public Health, University of Guadalajara, Guadalajara, Jalisco, Mexico. ${ }^{6}$ Corporación Sanitaria Parc Taulí de Sabadell, Barcelona, Spain. ${ }^{7}$ Hospital Universitario Principe de Asturias, Madrid, Spain. ${ }^{8}$ Universidad Anáhuac, Naucalpan de Juárez, Mexico. ${ }^{9}$ Department of Social Medicine, Ribeirão Preto Medical School, University of São Paulo, Ribeirão Preto, Brazil. ${ }^{10}$ Hospital Nacional de Niños, de Costa Rica Dr. Carlos Sáenz Herrera, San José, Costa Rica. ${ }^{11}$ Ministry of Health, Riyadh, Saudi Arabia. ${ }^{12}$ Department of Pediatrics and Hand Hygiene and Infection Control Research Center, Imam Reza Hospital, Mashhad University of Medical Sciences, Mashhad, Iran. ${ }^{13}$ Infection Control Africa Network, Unit of IPC, Tygerberg Hospital, Cape Town, South Africa. ${ }^{14}$ Department of Statistics and Operations Research, Faculty of Science, University of Malta, Msida, Malta. ${ }^{15}$ Infection Prevention and Control Global Unit, Department of Service Delivery and Safety, World Health Organization, Geneva, Switzerland. ${ }^{16}$ Department of Infectious Diseases, Centro Hospitalar Lisboa Norte and Faculdade de Medicina da Universidade de Lisboa, Lisbon, Portugal.
}

Published online: 31 January 2020

\section{Reference}

1. Tartari $E$, et al. Train-the-Trainers in hand hygiene: a standardized approach to guide education in infection prevention and control. Antimicrob Resist Infect Control. 2019;8:206 https://doi.org/10.1186/s13756-019-0666-4.

The original article can be found online at https://doi.org/10.1186/s13756019-0666-4

* Correspondence: didier.pittet@hcuge.ch

${ }^{1}$ Infection Control Programme and WHO Collaborating Centre on Patient

Safety, University of Geneva Hospitals and Faculty of Medicine, 4 Rue

Gabrielle-Perret-Gentil, 1211 Geneva, Switzerland

Full list of author information is available at the end of the article

(c) The Author(s). 2020 Open Access This article is distributed under the terms of the Creative Commons Attribution 4.0 International License (http://creativecommons.org/licenses/by/4.0/), which permits unrestricted use, distribution, and reproduction in any medium, provided you give appropriate credit to the original author(s) and the source, provide a link to the Creative Commons license, and indicate if changes were made. The Creative Commons Public Domain Dedication waiver (http://creativecommons.org/publicdomain/zero/1.0/) applies to the data made available in this article, unless otherwise stated. 